\title{
A GENÉTICA FORENSE NO LIVRO DIDÁTICO DE BIOLOGIA: Uma abordagem investigativa
}

\author{
Lindomar Gomes dos Santos ${ }^{1}$, Lilian Gomes dos Santos ${ }^{2}$, José Maria Bueno de Moraes \\ Júnior ${ }^{3}$.
}

1Mestrando em Educação em Ciências e Matemática, Universidade Federal de Goiás (lin_gomez@hotmail.com).

2 Especialista em Tecnologias Aplicadas ao Ensino de Biologia, Universidade Federal de Goiás.

3 Especialista em Inovação em Mídias Interativas, Universidade Federal de Goiás.

Recebido em: 03/10/2016 - Aprovado em: 21/11/2016 - Publicado em: 05/12/2016 DOI: 10.18677/EnciBio 2016B 142

\section{RESUMO}

Devido à velocidade das descobertas na área da genética é comum que alguns temas relativamente importantes fiquem fora da grade curricular das séries do Ensino Médio. O DNA Forense, ou Genética Forense é um dos temas de grande repercussão na mídia da atualidade, por sua utilização na resolução de casos de crime pela perícia criminal e também em casos civis, como testes de paternidade. Em razão disso não é raro, que os professores tenham que abordar esse tema em sala de aula, atendendo aos anseios dos alunos, todavia nem sempre é fácil encontrar no livro didático uma abordagem adequada ao assunto, para que o professor se norteie no planejamento de aula. De fato o livro didático é ainda o principal instrumento de trabalho, pois é a partir deste que são elaborados os planejamentos mensais e anuais, bem como o plano de aula, pois muitas vezes o uso de outros recursos é inviável por falta de estrutura adequada da escola. Neste trabalho foi feita uma análise sobre como o DNA Forense é tratado nos livros didáticos de Biologia para o Ensino Médio, nas edições de volume único, de diversas editoras e épocas, verificando o aprofundamento teórico das sessões destinadas a esse tema. Foram escolhidas 10 obras para análise. Os resultados constataram que $40 \%$ dos livros didáticos abordam a Genética Forense de maneira aprofundada e $60 \%$ de forma superficial, o que já demonstra uma preocupação com a inclusão de temas atuais da biologia nos livros didáticos, seguindo as orientações dos PCN.

PALAVRAS-CHAVE: DNA Forense, Livro Didático, Ensino de Biologia.

\section{FORENSIC GENETICS IN BIOLOGY TEXTBOOK: An investigative approach}

\footnotetext{
ABSTRACT

Due to the speed of discoveries in genetics, it is common that some fairly important issues remain outside the curriculum of high schools. DNA Forensic or Forensic Genetics is one of the high-profile issues in today's media, because of its use in solving criminal cases by the criminal expertise team and in civil cases, such as paternity testing. For this reason, it is not rare that teachers have to approach this topic in the classroom, taking into account the desires of students, yet it is not always ENCICLOPÉDIA BIOSFERA, Centro Científico Conhecer - Goiânia, v.13 n.24; p.1540 
easy to find in the textbook an appropriate approach to the subject, so that the teacher is guided when planning for his or her class. In fact, the textbook is still the main instrument of work, because it is from it that monthly and annual plans are made as well as the lesson plan, since often, the use of other resources is not feasible due to the lack of adequate structure of the school. In this article, an analysis was made of how the Forensic DNA is treated in Biology textbooks for High Schools, the single volume editions, from several publishers and periods of times, checking the theoretical deepening sessions for this topic. Ten books were selected for analysis. The results found that $40 \%$ of the textbooks address the Forensic Genetics in depth and $60 \%$ in a superficial manner, which already shows a concern with the inclusion of current issues in biology textbooks, following the guidelines of the NCP.

KEYWORDS: DNA Forensics, Textbook, Biology Teaching.

\title{
INTRODUÇÃO
}

Os livros didáticos (LD) são considerados agentes determinantes de currículos, limitando a inserção de novas abordagens e possibilidades de contextualização do conhecimento (CAVAGNOLI \& SOARES, 2009). Devido à velocidade das descobertas na área da genética é comum que alguns temas relativamente importantes fiquem de fora da grade curricular das séries do Ensino Médio. Um exemplo de um desses temas é a Genética Forense ou DNA Forense. $O$ mesmo ocorre com outros temas que fazem parte da chamada "Nova Biologia", ou "Biologia Moderna", tais como: melhoramento genético, transgênicos, clonagem, terapia gênica, células tronco. Muitos dos quais já estão sendo amplamente divulgados pela mídia desde a década de 1960, sem apresentar representação significativa nos livros didáticos (XAVIER et al., 2006).

O DNA Forense é um dos temas de grande repercussão na mídia da atualidade, em razão de sua utilização na resolução de casos de crime pela perícia criminal e também em casos civis, como testes de paternidade. PARADELA \& FIGUEIREDO (2006) explanam sobre o uso das análises de DNA e suas finalidades:

\begin{abstract}
As análises de DNA (ácido desoxirribonucléico), em virtude da sua presumida confiabilidade, são cada vez mais empregadas para fins judiciais, suplantando as tradicionais provas sorológicas. Os exames para a identificação humana por DNA podem ser utilizados para rapidamente estabelecer vínculo genético, exonerar falsos suspeitos ou relacionar criminosos a cenas de crime e estas entre si, acarretando significativa economia de tempo e dinheiro à justiça.
\end{abstract}

Em razão disso não é raro, que os professores tenham que abordar esse tema em sala de aula, atendendo aos anseios dos alunos, todavia nem sempre é fácil encontrar no livro didático uma abordagem adequada ao assunto, para que o professor se norteie no planejamento de aula. Uma vez que conteúdos biológicos, como DNA Forense, Eva Mitocondrial, Projeto Genoma, Sequenciamento Genético etc. há muito já discutidos e massificados pela mídia em todo o mundo, nem sempre têm a devida atenção e o devido espaço cabido a estes em alguns livros didáticos. Algumas iniciativas da inserção desse conteúdo no ensino médio podem ser observadas e o mais comum é o tratamento deste tema nas abordagens referentes à biotecnologia, demostrando nesse sentido a aplicação de modernas técnicas para exames de paternidade, investigação criminal, perícia etc., ou seja, alguns campos dos principais campos de atuação das tecnologias do DNA Forense. 
Os Parâmetros Curriculares Nacionais (PCNs) (BRASIL, 2002) abordam sobre a necessidade de o ensino de Biologia incluir debates e questões sobre novas tecnologias, em especial, temas da genética e da biologia molecular, como por exemplo, o DNA e a clonagem (GALANJAUSKAS, 2009 citado por SANTOS \& SANTOS, 2014).

Referente a essas recomendações, ARAÚJO et al. (2014) consideram o livro didático de biologia como sendo uma peça importante no processo de ensino e aprendizagem:

\begin{abstract}
O livro didático torna-se de fundamental importância no processo de ensino e aprendizagem principalmente nas escolas públicas pela carência de recursos didáticos disponíveis. Nesse sentido a analise e escolha deve ser bem fundamentada, para que este possa servir com excelência o publico alvo (ARAÚJO et al., 2014).
\end{abstract}

SILVA (2009) considera que os PCN do Ensino Médio (PCNEM) buscam dar significado ao conhecimento escolar, contextualizando os conhecimentos e se evitando a compartimentalização, usando para isso a interdisciplinaridade. Para a autora "a proposta da interdisciplinaridade é estabelecer ligações de complementaridade, convergência, interconexões e passagens entre os conhecimentos" (SILVA, 2009).

Neste sentido AMORIM (1999) citado por BRITO et al. (2008) mencionam que um dos caminhos para o rompimento do tradicionalismo na produção de conhecimento escolar é a inserção de novos conteúdos culturais que sejam capazes de provocar mudanças na compreensão da realidade e não apenas ilustrá-las ou estimulá-las.

Com a homogeneização aparente da "oferta" do ensino médio, visando à garantida de uma formação igualitária a todos que ingressassem e permanecessem na instituição escolar, que foi proposta pelo Ministério ocorreu o surgimento de dúvidas quanto ao real poder de transformação, pois, são minimizadas as condições históricas, culturais e econômicas dos sujeitos por ela atingidos (WEBER, 2007).

Para SCHWAB (1973) citado por MORAES (2005), o conteúdo "tem sido entendido como algo fixo, persistindo a ideia de que a ciência se desenvolve por acréscimo de novos conhecimentos. Neste sentido é que os livros didáticos apresentam-se cada vez mais extensos".

MORAES (2005) considera que "O que vê-se hoje nos livros textos de biologia do ensino médio é uma organização que inicia com o estudo das moléculas, terminando no estudo da biosfera". Já quanto à genética humana, Casagrande (2006) coloca que ela é tratada "geralmente quando são abordados assuntos como alelos múltiplos (grupos sanguíneos), herança quantitativa (cor da pele, cor dos olhos) ou quando são usados exemplos de doenças para ilustrar padrões mendelianos de herança ou alterações cromossômicas". Entretanto, o Plano Nacional do Livro Didático do Ensino Médio (PNLEM) é recomendado que os livros didáticos de Biologia apresentem conteúdo e procedimentos atualizados, referentes aos saberes da ciência e às orientações curriculares (CARDOSO-SILVA; OLIVEIRA, 2013).

Para Ferreira (2007) citado por SANTOS \& BELMINO (2013) o professor deve valer-se de recursos didáticos na sala de aula e que nesse momento "ele transfere os conhecimentos que estão expressos no livro para a realidade do educando", fazendo a chamada transposição didática dos conteúdos. 
Entretanto SOUZA \& SANTOS (2012) observam o fato de que o livro didático é ainda o principal instrumento de trabalho, pois é a partir deste que são elaborados os planejamentos mensais e anuais, bem como o plano de aula, pois muitas vezes o uso de outros recursos é inviável por falta de estrutura adequada da escola. Desta forma, conforme pontuam ARAÚJO et al. $(2014$, p. 3) "No ensino de ciência o livro didático torna-se um instrumento de fundamental importância, pois em muitos casos representa o único material didático disponível", ressaltando ainda mais o significado que o livro didático tem no ensino. Referente a isso, CICILLINI no ano de 1998, em estudos sobre a utilização dos livros didáticos pelos professores de Biologia no Ensino Médio, constatou que:

\begin{abstract}
Ainda que utilizassem outros textos como jornais e revistas, a relevância desses outros recursos no ensino de Biologia é pequena diante do valor que esses professores atribuíram às funções do livro didático e sua forma de utilização (CICILLINI, 1998, p.32)
\end{abstract}

Sendo essas algumas das razões que fazem com que o professor, nem sempre trabalhe temas tão atuais com os alunos, mesmo que estes tenham demonstrado curiosidade a respeito, como o já citado DNA Forense. Demonstrando assim, a "inquestionável importância do livro didático, como elemento estruturante das aulas de Ciências e Biologia" (CARDOSO-SILVA; OLIVEIRA, 2013, p. 171).

No entanto, apesar desse destaque que é dado pelos professores ao livro didático, é necessário se observar que, muitas vezes, as obras adotadas em escolas particulares são edições de volume único, que apresentam uma quantidade menor de conteúdos e de aprofundamento nas discussões. Já na rede pública, com a distribuição dos livros atendendo às exigências do PNLEM e do Ministério da Educação e Cultura (MEC), as obras adotadas sempre são coleções completas, com um volume a ser utilizado em cada respectivo ano.

Neste contexto, o presente trabalho tem por objetivo fazer uma análise sobre como o DNA Forense é tratado nos livros didáticos de Biologia para o Ensino Médio, especificamente nas edições de volume único.

\title{
MATERIAL E MÉTODOS
}

Esse estudo se baseou na escolha e análise do conteúdo dos livros didáticos de Biologia do Ensino Médio, nas edições de Volume Único, de diversas editoras, observando a ocorrência ou não de abordagens sobre o DNA Forense, verificando ainda o aprofundamento teórico das sessões destinadas a esse tema.

Os livros escolhidos para análise são edição de volume único, em razão da redução de conteúdos que estes apresentam se comparados aos livros de Biologia do Ensino Médio em três volumes adotados e distribuídos pelo MEC. Na escolha das obras buscou-se contemplar tanto produções de diferentes autores e editoras, quanto épocas distintas, na tentativa de se estabelecer um panorama analítico da diversidade dos livros didáticos disponíveis para venda e, portanto passíveis de serem utilizados pelos professores de Biologia no Ensino Médio, seja como livro referência ou como material complementar, utilizado nas elaborações de conteúdos paras aulas e planejamentos, entre outros. E para que também se pudesse acompanhar evolução da abordagem do DNA Forense nos livros didáticos, ao longo do tempo.

Para seleção dos livros inicialmente foi realizada uma leitura exploratória dos livros disponíveis para venda em livrarias da cidade de Goiânia, identificando as 
obras que poderiam ser utilizadas na pesquisa e com isso foram selecionadas 10 publicações, que abarcaram o período entre 1998 e 2010. Na fase seguinte, teve-se início da análise dos livros e a subdivisão em categorias relativas ao DNA forense. A seguir é apresentada uma tabela do material selecionado para este estudo (Tabela 1).

TABELA 1 - Referência bibliográfica dos Livros Didáticos (LD) selecionados para este estudo

\begin{tabular}{|c|c|c|c|c|}
\hline LD & Título da Obra & Editora & Autor(es) & $\begin{array}{l}\text { Ano de } \\
\text { edição }\end{array}$ \\
\hline L1 & Biologia & Atual & Ayrton Marcondes & 1998 \\
\hline $\mathbf{L} 2$ & Biologia em Foco & FTD & Wanderley Carvalho & 2002 \\
\hline L3 & Biologia Integrada & FTD & Luiz Eduardo Cheida & 2003 \\
\hline L4 & Biologia & Harbra & $\begin{array}{l}\text { Armênio Uzuniam e } \\
\text { Ernesto Birner }\end{array}$ & 2004 \\
\hline L5 & Biologia & Moderna & $\begin{array}{c}\text { José Arnaldo } \\
\text { Favaretto e Clarinda } \\
\text { Mercadante }\end{array}$ & 2005 \\
\hline L6 & Fundamentos da Biologia Moderna & Moderna & $\begin{array}{c}\text { José Mariano Amabis } \\
\text { e Gillberto Rodrigues } \\
\text { Martho }\end{array}$ & 2007 \\
\hline L7 & Biologia & Saraiva & César e Sezar & 2007 \\
\hline L8 & Série Novo Ensino Médio & Ática & $\begin{array}{l}\text { Wilson Roberto } \\
\text { Paulino }\end{array}$ & 2008 \\
\hline L9 & Bio & Saraiva & $\begin{array}{c}\text { Sônia Lopes e Sérgio } \\
\text { Rosso }\end{array}$ & 2009 \\
\hline L10 & Biologia Hoje & Ática & $\begin{array}{c}\text { Sérgio Linhares e } \\
\text { Fernando } \\
\text { Gewandsznajder }\end{array}$ & 2010 \\
\hline
\end{tabular}

Fonte: Autores

Tendo-se como critério a profundidade das discussões encontradas durante a leitura exploratória das obras, estabeleceram-se cinco categorias para análise de abordagem ao tema:

A. Abordagem completa sobre DNA Forense. Considerando-se dessa forma os livros que trouxessem a respeito dos aspectos genéticos e moleculares e também dos aspectos legais envolvidos na definição do que é o DNA Forense. Devendo estes discorrer sobre os conceitos fundamentais e aplicações, tais como: DNA fingerprinting, Identificação de pessoas por DNA, Técnicas utilizadas para análise de DNA, Perícia Criminal, Teste de DNA, Reconhecimento de Paternidade, entre outros;

B. Abordagem superficial sobre os aspectos legais do DNA Forense. Sendo assim consideradas as obras que apenas tratassem do tema, em seus aspectos jurídicos e que não esclarecessem os conceitos biológicos envolvidos;

C. Abordagem superficial sobre os aspectos genéticos e moleculares do DNA Forense. Considerando assim os livros que discorressem apenas sobre a fundamentação biológica do tema, como por exemplo: Genoma Humano, Testes de DNA, Perfil Genético etc., sem fazer a associação com o uso nas práticas judiciais; D. Abordagem de temas correlatos ao DNA Forense. Tais como: DNA mitocondrial, eletroforese, PCR (Polymerase Chain Reaction), Cromossomo Y, Banco Genético, entre outros, que não fossem textualmente associados ao DNA Forense, mas que poderiam facilitar a inserção dessa temática no transcorrer de uma aula. 
E. Não aborda de nenhuma forma sobre o tema. Sendo consideradas assim as obras em que não fossem encontrados nem os aspectos biológicos do DNA forense e nem menção aos aspectos jurídicos envolvidos na utilização.

\section{RESULTADOS E DISCUSSÃO}

Ao analisar as 10 obras, seguindo as especificações de cada um dos 5 critérios, tem-se os seguintes resultados, conforme demonstra a Tabela 2.

TABELA 2 - Resultado da análise dos Livros Didáticos de Ensino Médio

\begin{tabular}{|c|c|c|c|c|c|}
\hline LD & $\begin{array}{c}\text { Abordagem } \\
\text { Completa }\end{array}$ & $\begin{array}{l}\text { Superficial } \\
\text { Aspectos } \\
\text { Legais }\end{array}$ & $\begin{array}{l}\text { Superficial } \\
\text { Genéticos e } \\
\text { moleculares }\end{array}$ & $\begin{array}{c}\text { Presença de } \\
\text { Correlatos }\end{array}$ & $\begin{array}{l}\text { Não } \\
\text { Aborda }\end{array}$ \\
\hline L1 & & & $\mathbf{X}$ & $\mathbf{X}$ & \\
\hline L2 & & & $\mathbf{X}$ & $\mathbf{X}$ & \\
\hline L3 & & & $\mathbf{X}$ & $\mathbf{X}$ & \\
\hline L4 & $\mathbf{X}$ & & & $\mathbf{X}$ & \\
\hline L5 & & & $\mathbf{X}$ & $\mathbf{X}$ & \\
\hline L6 & $\mathbf{X}$ & & & $\mathbf{X}$ & \\
\hline L7 & $\mathbf{X}$ & & & $\mathbf{X}$ & \\
\hline L8 & & & $\mathbf{X}$ & $\mathbf{X}$ & \\
\hline L9 & $\mathbf{X}$ & & & $\mathbf{X}$ & \\
\hline L10 & & & $\mathbf{X}$ & $\mathbf{X}$ & \\
\hline
\end{tabular}

Fonte: Autores

Quanto à análise dos livros didáticos, os resultados demonstraram que encontram-se diversos livros que tratam sobre o DNA Forense no nível Médio de Ensino. Uma vez que das 10 obras analisadas, todas tratam de alguma forma a esse respeito. Nesse sentido BADZINSKI \& HERMEL (2015) consideram que os conhecimentos oriundos das ciências, em especial da genética e da evolução, estão cada vez mais presentes nas vidas dos indivíduos, o que torna fundamental que todos tenham pelo menos noções básicas sobre esses assuntos. Todavia os livros didáticos, por vezes, não contemplam essa ideia, ao deixarem de valorizar o vínculo do conhecimento científico com a realidade (CARDOSO-SILVA; OLIVEIRA, 2013).

Entretanto, faz-se necessário observar que em 4 das 10 obras analisadas, ou seja, $40 \%$ do total, o assunto é tratado de forma aprofundada, com a destinação de capítulos inteiros sobre conceitos fundamentais do tema, como DNA fingerprinting, micro e minissatélites, identificação de pessoas pelo DNA, o uso da Reação em cadeia da polimerase (PCR - sigla em inglês) e principalmente, nestas obras é feita a relação com as finalidades legais da análise, que é o que caracteriza o DNA Forense.

A título de exemplo do que foi considerado como sendo Abordagem Aprofundada, pode-se citar a obra L9. O livro além de dedicar uma sessão inteira a conteúdos de biotecnologia, traz um capítulo especialmente dedicado à identificação de pessoas pelo DNA. Fazendo um esclarecimento do uso em finalidades criminais, testes de paternidade, criação de perfil genético, bem como apresentando um detalhamento sobre as técnicas de análise PCR e Restriction Fragment Length 
Polymorphism (RFLP - singla em inglês, em português Polimorfismo nos Fragmentos de Restrição), ilustrando como são feitas, a criação das bandas e sondas, demonstrando dessa forma um maior aprofundamento no tratamento do tema DNA Forense. Neste quesito, destaque também para o livro didático L7.

Nesse sentido, as obras enquadradas nessa categoria se assemelham às definições que ARAÚJO et al. (2014) pontuaram sobre o papel do livro didático de Biologia "[...] é necessário que este possa oferecer o conteúdo de forma eficaz, a compreensão e ao desenvolvimento cognitivo no processo de aprendizado dos discentes", tanto em razão do texto apresentado, quanto pela forma de abordagens e conceitos, podendo facilitar com que o professor contextualize o conteúdo ao saber do aluno e ao seu cotidiano.

Já nas outras 6 (60\% do total), em que considerou-se que abordam de forma superficial o tema, o assunto era abordado, principalmente, no tocante aos aspectos de conceituação biológica (genéticos e moleculares), sem que fosse feita, no entanto, nenhuma menção a utilização judicial das análises de DNA, por exemplo.

Com respeito a essas obras consideradas como de Abordagem superficial sobre os aspectos genéticos e moleculares do DNA Forense, pode-se citar como exemplo a obra L10. O livro em edição de volume único, apesar de trazer um grande panorama de conceitos biológicos (genéticos e moleculares) a respeito do DNA e da prerrogativa de ser individual, não faz nenhuma menção à utilização em procedimentos de perícia criminal, identificação de cadáveres, processos civis e criminais, que é o que contempla os atributos da definição de DNA forense. Nesse sentido destaque para o livro didático L1, publicado em 1998, pois já nessa época apresentava material a respeito dessa temática, o que não era tão comum em outros livros didáticos da mesma época.

Com relação ao DNA Forense, esse porcentual encontrado de $60 \%$ demonstra um quadro que já fora estabelecido e discutido por CARDOSO-SILVA \& OLIVEIRA em 2013, "O conteúdo didático relacionado às pesquisas com o uso da molécula de DNA é abordado de modo restrito, por vezes, de forma equivocada e dirigida somente a aspectos biológicos relativos à Genética humana [...]". Validando assim, em nossa análise, o cenário que também já fora descrito por outros autores.

Esses autores observam o fato de que nos PCN do Ensino Médio, o DNA é apontado como um conteúdo que pode ser trabalhado de forma interdisciplinar e de modo a contemplar os avanços científicos e tecnológicos (CARDOSO-SILVA \& OLIVEIRA, 2013), todavia a maioria das obras analisadas neste esstudo, ainda se restringiram apenas aos conceitos biológicos, sem estabelecer uma relação de contextualidade do estudo da molécula para análises forenses, que é o que caracteriza a Genética Forense.

BADZINSKI \& HERMEL (2015) observam que os estudos relacionados à genética estão presentes por praticamente toda educação básica, se iniciando no Ensino Fundamental e com aprofundamento no Ensino Médio. Em contrapartida é nesse mesmo período que surge certo receio com esses conteúdos, devido aos conceitos muitas vezes parecerem abstratos. CARDOSO-SILVA \& OLIVEIRA (2013) ainda acrescentam que "[...] do modo que a temática é apresentada nos livros didáticos, fica difícil despertar o interesse dos alunos em optar pela carreira de pesquisa nesta área da ciência". Referente a isso ARAÚJO et al. (2014) observam que a análise, escolha e avalição do livro didático são imprescindíveis, uma vez que este serve como referencial teórico para o planejamento das atividades de ensino e fundamenta o desdobramento em aprendizagem. 
Com relação à Abordagem de temas correlatos ao DNA Forense, tais como: DNA mitocondrial, eletroforese, PCR, Cromossomo Y, Banco Genético, entre outros, notou-se que em todas as obras analisadas, abordava-se a essas temáticas, mesmo que restritas a pequenos trechos em parágrafos ou em Textos de Apoio. Em razão disso, a presença destes fatores tornaria propícia a inserção da temática DNA Forense no decorrer do uso do livro didático em sala de aula, favorecendo assim uma discussão sobre o tema. Neste sentido, o professor tem o papel fundamental na escolha dos critérios utilizados para inserir este conteúdo em sala de aula, pois conforme pontuam BADZINSKI \& HERMEL (2015), "é o professor que deve conduzir a utilização do livro didático e não o contrário".

Observou-se ainda, que nenhuma das 10 obras, fez somente uma Abordagem superficial sobre os aspectos legais do DNA Forense, sem que fossem feitas as devidas considerações de fundamentação biológica, o que já era um resultado esperado, pois dificilmente seria encontrado em um livro de Biologia, mesmo que em uma edição de volume único, algum conteúdo referente ao DNA, sem que se fossem explanados os aspectos genéticos e moleculares do conteúdo e somente se ativesse à utilização forense.

\section{CONCLUSÃO}

Com a análise também ficou demonstrado, que o assunto era abordado em todas, mesmo que de forma superficial e indireta, como no caso dos temas correlatos ou apenas tratando das definições biológicas das análises de DNA, sem a contemplação das aplicações em práticas forenses.

Em razão disso, como a análise dos livros demonstrou, com o passar dos anos as edições dos livros didáticos em suas reformulações passaram a abordar aspectos e conteúdos que não tratavam anteriormente. O fato de $40 \%$ das obras já incluírem um aprofundamento nas discussões sobre DNA, contemplando as utilizações jurídicas, demonstra uma tendência de ao longo do tempo, das editoras e dos autores em incluírem em suas publicações os temas mais atuais de discussão no meio científico. Todavia o percentual de $60 \%$ das publicações se aterem especificamente aos aspectos biológicos do DNA, torna-se de certo modo preocupante, pois muitos professores ainda se baseiam nessas publicações para fazerem planejamentos de aula, o que evidencia a necessidade da atualização no Ensino em sala de aula, pois muitas vezes, esses temas considerados "novos", como é o caso do DNA Forense ficam relegados a segundo plano, por não estarem incluídos nos livros didáticos utilizados pelo professor.

A Genética Forense ou DNA Forense é uma área relativamente nova e que traz consigo uma grande divulgação midiática, tanto em obras de ficção como seriados e filmes, quanto por resoluções de casos criminais de grande complexidade, o que acaba por despertar o imaginário e a curiosidade dos alunos, em razão disso a abordagem em sala de aula demanda todo um preparo e arcabouço teórico dos quais o professor deve estar munido, para lidar com as expectativas dos alunos. Sendo que ao se trabalhar esse conteúdo com os alunos, pode-se contribuir para uma revisão de conceitos de genética e biologia molecular e contribuir para uma aprendizagem significativa.

Posto isso, torna-se necessário ressaltar que, o referencial teórico do professor não deve se restringir apenas à utilização de livros didáticos, uma vez em que, nem sempre a obra adotada, é capaz de contemplar os temas de relevância na atualidade. Cabendo o uso do bom senso do profissional Educador no 
direcionamento, que deve ser dado a essas abordagens, quando ele está à frente da disciplina e auxiliando os alunos na construção do próprio conhecimento.

\section{REFERÊNCIAS}

ARAÚJJ, J.; ALMEIDA, J.; BRANDÃO, L.; CUNHA, C. Análise do livro didático de Biologia em relação à abordagem da temática lixo. 2014. Disponível em: <http://hdl.handle.net/10438/11377>. Acesso em 11 mai. 2016.

BADZINSK, C.; HERMEL, E. E. S. A representação da genética e da evolução através de imagens utilizadas em livros didáticos de biologia. Revista Ensaio. Belo Horizonte, v.17, n. 2, p. 434-454, maio-ago, 2015. Disponível em: <http://dx.doi.org/10.1590/1983-21172015170208>.

BRASIL, Ministério da Educação e Cultura. PCN Ensino Médio: Orientações educacionais complementares dos parâmetros curriculares nacionais. Brasília. 2002.

BRITO, L. D.; SOUZA, M. L.; FREITAS, D. Formação inicial de professores de Ciências e Biologia: a visão da natureza do conhecimento científico e a relação CTSA. $2008 . \quad$ Disponível em: $<$ http://repositorio.ipsantarem.pt/bitstream/10400.15/301/1/l7.pdf>. Acesso em 1 jun. 2016.

CARDOSO-SILVA, C. B.; OLIVEIRA, A. C. Como os livros didáticos de biologia abordam as diferentes formas de estimar a biodiversidade? Ciência \& Educação, v. 19, n. 1, p. 169-180, 2013. Disponível em: <http://dx.doi.org/10.1590/S1516$73132013000100012>$.

CASAGRANDE, G. L. A genética humana no livro didático de biologia. Florianópolis, 2006. 102 f. Dissertação (Mestrado em Educação Científica e Tecnológica) - Universidade Federal de Santa Catarina.

CAVAGNOLI, S. R.; SOARES, M. A. M.. Desmistificando A Biotecnologia. 2009. Disponível em: $<$ http://www.gestaoescolar.diaadia.pr.gov.br/arquivos/File/producoes_pde/artigo_sonia_regina_cavagnoli.pdf >. Acesso em 10 jan. 2016.

CICILLINI, G. A. Ensino de Biologia: o livro didático e a prática pedagógica dos professores no Ensino Médio. Ensino em Re-Vista, 6 (1): 29-37, jul. 97./jun. 98. Disponível em: <http://www.seer.ufu.br/index.php/emrevista/article/view/7834/4941>.

MORAES, R. M. A aprendizagem significativa de conteúdos de biologia no ensino médio, mediante o uso de organizadores prévios e mapas conceituais. Campo Grande, 2005. 147 f. Dissertação (Mestrado em Educação) - Mestrado em Educação da Universidade Católica Dom Bosco.

PARADELA, E. R.; FIGUEIREDO, A. L. S. O DNA vai para o tribunal: O impacto das tipagens genéticas. 2006.2 Disponível em: $<$ www.buscalegis.ufsc.br/revistas/files/anexos/9857-9856-1-PB.pdf>. Acesso em 28 fev. 2016. 
SANTOS, L. G; SANTOS, R. S. Ensinando genética evolutiva e evolução humana sob a ótica da teoria da Eva mitocondrial. Revista Sapiência: sociedade, saberes e práticas educacionais - UEG/Campus de Iporá, v.3, n. 2, p.158-177 - jul/dez 2014.

SANTOS, O. K. C.; BELMINO, J. F. B. Recursos didáticos: uma melhoria na qualidade da aprendizagem. 2013. Disponível em: <http://editorarealize.com.br/revistas/fiped/trabalhos/Trabalho_Comunicacao_oral_idi nscrito_fde094c18ce8ce27adf61aedf31dd2d6.pdf>. Acesso em 1 jun. 2015.

SILVA, S. M. M. PCN - Ensino Médio. 2009. Disponível em: <http://www.slideshare.net/tetafg/pcn-ensino-mdio-presentation>. Acesso em 24 mar. 2016.

SOUZA, R. M.; SANTOS, M. M.. Análise da prática pedagógica em educação ambiental no contexto de escola rural em Itaporanga d'ajuda-se. Revista VITAS Visões Transdisciplinares sobre Ambiente e Sociedade. № 2, janeiro de 2012. Disponível em: <http://www.uff.br/revistavitas/images/artigos/r2/As\%20pr\%C3\%A1ticas\%20escolare s\%20de\%20Educa\%C3\%A7\%C3\%A30\%20Ambiental\%20de\%20professoras\%20MMS\%20e\%20RMSrevisado.pdf.>.

WEBER, M. R. G. F. A Reformulação do Ensino Médio na Década de 1990. 2007. Disponível em: <www.pucpr.br/eventos/educere/educere2007/.../Cl-167-01.pdf>. Acesso em 22 set. 2016.

XAVIER, M. C. F; FREIRE, A. S.; MORAES, M. O. A Nova (Moderna) Biologia e a Genética nos Livros Didáticos de Biologia no Ensino Médio. Ciência \& Educação, v. 12, n. 3, p. 275-289, 2006. Disponível em: $<$ www.redalyc.org/pdf/2510/251019510003.pdf $>$. 